\title{
Quantifying external and internal nitrogen and phosphorus pools, as well as nitrogen and phosphorus supplied through remineralization, in coastal marine plankton by means of a dilution technique
}

\author{
T. Andersen, A. K. L. Schartau, E. Paasche*
}

Section for Marine Botany, Department of Biology, University of Oslo, PO Box 1069, Blindern, N-0316 Oslo 3, Norway

\begin{abstract}
A theoretical framework was developed for analyzing Landry \& Hassett (1982; Mar. Biol. 67: 283-288) type dilution assays under more general conditions, where phytoplankton growth might also be nutrient-limited. The theory, which accounts for growth on available internal and external pools as well as on nutrients supplied through remineralization by grazers, was applied to a series of field experiments performed in nutrient-impoverished waters in the Oslofjord, Southern Norway, in summer 1988. Analysis of the experimental results indicates that the phytoplankton had intracellular stores of $P$ sufficient for several hours of growth in all experiments, while internal stores of $\mathrm{N}$ were undetectable in 4 out of 6 cases. Dissolved N pools appeared to be of greater importance to the algae as a nutrient reservoir than were dissolved P pools. Significant nutrient supplies from remineralization were identified on 3 out of 6 occasions, compensating for around half of the estimated grazing losses in each case. The supplies of remineralized $\mathrm{N}$ and $\mathrm{P}$ were closely balanced with respect to the growth demands of the phytoplankton, indicating that the surplus of cellular P originated from other sources.
\end{abstract}

\section{INTRODUCTION}

In stratified waters, concentrations of dissolved inorganic pools of both nitrogen (DIN) and phosphorus (DIP) are typically low, and may approach the limits of detection. However, low DIP and DIN concentrations do not necessarily mean that phytoplankton growth is under strong nutrient control, since the pools may be rapidly renewed through remineralization of $\mathrm{N}$ and $\mathrm{P}$ by heterotrophs (Harrison 1983, Glibert 1988), as well as through physical admixture. Besides, there may be sources of nutrients, other than the ordinary inorganic ions, that are not included in usual sampling programs.

A variety of tests have been applied in an effort to demonstrate physiological nutrient limitation in phytoplankton (Hecky \& Kilham 1988). Many of them

- Addressee for correspondence depend heavily on extrapolation from laboratory studies of cultured phytoplankton. At one time, 'all minus one' growth tests were extensively used (e.g. Ryther \& Guillard 1959, Ryther \& Dunstan 1971, Smayda 1974). In these tests, aliquots of seawater containing the resident plankton algae are selectively enriched, leaving out one of the nutrients $(\mathrm{N}, \mathrm{P}$, and so on) at a time, and comparing the growth yields in the different treatments after several days. The final yield in such experiments depends both on the residual concentrations of dissolved nutrients in the water and on the internal nutrient reserves in the cells. Conventional 'all minus one' tests are incapable of resolving the contribution of residual external nutrients relative to that of internal reserves. Droop and others (see Droop 1983) showed the latter to be important in the nutrient economy of plankton algae, and recent research into nutrient limitation has focused on measurements of cellular $\mathrm{N}$ and $\mathrm{P}$, expressed e.g. as C:N:P elemental ratios (Sakshaug \& Olsen 1986) or as internal 
concentrations of storage products, such as amino acids (Dortch et al. 1984) or polyphosphates (Miyata et al. 1986).

In an effort to identify internal and external $\mathrm{N}$ and $\mathrm{P}$ sources in waters low in DIN and DIP, we have used an 'all minus one' approach in combination with the dilution technique of Landry \& Hassett (1982). Their method was developed as a tool in quantifying microzooplankton grazing and has subsequently been used with further refinements by Burkill et al. (1987), Paranjape (1987), Gifford (1988), and Gallegos (1989). Landry \& Hassett (1982) did not think the dilution technique would yield useful results in low-nutrient waters unless potentially limiting nutrients were added to the experimental bottles. This was because the experiments had to run through a $24 \mathrm{~h}$ day-night cycle, during which time DIN and DIP might become exhausted. Landry \& Hassett therefore added $\mathrm{N}$ and $\mathrm{P}$ in excess, a practice which was usually followed in subsequent studies. The potential of their method in studies of nutrient limitation has not so far been explored.

The original technique involves the determination of apparent (i.e. net) algal growth rates measured in plankton samples diluted to various degrees with filtered seawater. The true growth rate is found by extrapolation to infinite dilution. If nutrients are in excess, the lowering of apparent growth rate relative to true rate can be ascribed to grazing (Landry \& Hassett 1982). A further depression of apparent growth rate occurs if nutrients are exhausted before the experiment is terminated. This effect is relieved by dilution, because any external $\mathrm{N}$ and $\mathrm{P}$ reserves present in solution are shared among fewer algal cells and therefore last longer. On the other hand, the supply rate of recycled nutrients from herbivores is also reduced by dilution. This reduction is caused partly by the direct effect of dilution on grazer abundance and partly by the indirect effect arising from reduced food consumption due to a diluted food supply. Therefore, if a proper correction can be made for grazing, selective enrichment with $\mathrm{N}$ in dilution experiments can be used to assess the relative magnitudes of both the external and internal pools of $\mathrm{P}$ and the supply of recycled $\mathrm{P}$ from grazers. Similarly, $\mathrm{P}$ enrichment will give information on the $\mathrm{N}$ pools and $\mathrm{N}$ recycling.

We have applied this reasoning in experiments carried out in summer situations in the Oslofjord, Norway. The Oslofjord is stratified in the summer, with DIN and DIP levels above the pycnocline frequently approaching the detection limit (Paasche \& Erga 1988). The present work was adjunct to a $2 \mathrm{yr}$ investigation of the heterotrophic microplankton in the Oslofjord, the results of which will be published later (Schartau \& Paasche unpubl.).

\section{MATERIALS AND METHODS}

Sampling site and general sampling procedures. The experiments were carried out on 6 dates from May to August 1988, on 4 of them in the inner Oslofjord $\left(59^{\circ} 49^{\prime} \mathrm{N}, 10^{\circ} 32^{\prime} \mathrm{E}\right)$ and on the remaining 2 in the outer fjord $\left(59^{\circ} 14^{\prime} \mathrm{N}, 10^{\circ} 38^{\prime} \mathrm{E}\right)$. The water depth at the 2 stations is $>90 \mathrm{~m}$ and $>300 \mathrm{~m}$, respectively. Watercolumn data on hydrography (temperature, salinity, density) and nutrient concentrations $\left(\mathrm{PO}_{4}, \mathrm{NH}_{4}, \mathrm{NO}_{3}\right.$ including $\mathrm{NO}_{2}$, analysed on filtered samples) were obtained as described by Paasche \& Erga (1988).

Subsamples for the enumeration of phytoplankton were taken from the water used in experiments. The larger algae (diatoms and dinoflagellates) were counted in settling cylinders in an inverted microscope, the smaller ones (autotrophic flagellates) on blackened polycarbonate filters in an epifluorescence microscope. The cell volume of each species (diatoms and dinoflagellates) or size class (autotrophic flagellates) was calculated from linear dimensions and converted to cell carbon using the formulas of Strathmann (1967). This information, together with cell counts, was used to compute carbon standing stocks ( $\mathrm{pg} \mathrm{C}^{-1}$ ). These in turn were converted to chlorophyll $a(\mathrm{chl} a)$ by means of a chlorophyll:carbon ratio of 0.025 for diatoms, 0.01 for dinoflagellates, and 0.02 for other flagellates (Chan 1980, Langdon 1987). On this basis, an estimate was made of the percent share in total chlorophyll of main phytoplankton components.

Experimental procedure. The experiments were performed essentially according to Landry \& Hassett (1982), using changes in chl a concentrations as a measure of growth. Water was siphoned at noon from a depth of $2 \mathrm{~m}$ (inner fjord) or 1 to $4 \mathrm{~m}$ (outer fjord) through acid-washed PVC tubing into an evacuated 101 glass flask. Straining through zooplankton netting was omitted, as macrozooplankton is rare above the thermocline in the Oslofjord during summer. A portion of the water was filtered through previously acidwashed and combusted Whatman GF/C glass-fibre filters, taking care not to let the filters go dry. Filtered and unfiltered water was mixed to give 4 dilution steps. The precise proportions, expressed as 'fraction undiluted plankton' in the dilution diagrams presented below, were calculated from initial chl a concentrations and varied somewhat from experiment to experiment.

One set of samples (termed $+\mathrm{N}+\mathrm{P}$ ) received a complete nutrient enrichment consisting of $10 \mu \mathrm{M} \mathrm{NH}_{4} \mathrm{Cl}_{\text {, }}$ $1 \mu \mathrm{M} \mathrm{KH}_{2} \mathrm{PO}_{4}, 5 \mu \mathrm{M} \mathrm{Si}(\mathrm{OH})_{4}, 1 \mu \mathrm{M} \mathrm{Na} \mathrm{N}_{2}$ EDTA, $0.1 \mu \mathrm{M}$ $\mathrm{FeSO}_{4}$, and $0.01 \mu \mathrm{M} \mathrm{MnCl}_{2}$. A second set $(-\mathrm{N})$ was enriched with all these additions except $\mathrm{NH}_{4} \mathrm{Cl}$, and a third $(-\mathrm{P})$ with all except $\mathrm{KH}_{2} \mathrm{PO}_{4}$. Assuming reasonable values of $\mathrm{N}: \mathrm{chl} a$ and $\mathrm{P}: \mathrm{chl} a$, and of the Si content of diatom species predominant in May and July (cf. 
Paasche 1980), it can be calculated that the N, P and Si enrichments sufficed for an increase in chlorophyll standing stock of about 2 doublings per $24 \mathrm{~h}$ in undiluted samples in all experiments.

The samples were distributed in acid-washed 11 polycarbonate bottles with teflon-lined caps, with 2 bottles for each combination of nutrient enrichment and degree of dilution. The 24 bottles were incubated on deck for $24 \mathrm{~h}$ under natural illumination reduced by neutral screening to the in situ quantum flux, and were fastened to a slowly revolving wheel in a transparent tank cooled to ambient seawater temperature by running water from the ship's pump.

$\mathrm{Chl}$ a measurements were carried out in 6 replicates for each dilution step at the beginning of incubation and in 4 replicates from each bottle at the termination of the same. Samples $(50 \mathrm{ml})$ were filtered onto Whatman GF/C glass-fibre filters and chlorophyll was extracted with $10 \mathrm{ml}$ of $90 \%$ acetone. Fluorescence before and after acidification was read in a Turner Designs Model 10-000R fluorometer, and the chl a concentration, corrected for phaeopigments, was calculated from the decrease in fluorescence according to Holm-Hansen et al. (1965). The precision of these measurements was high, with a relative standard deviation of $3.1 \%(n=36)$.

In the experiment on 25 May, when the plankton was dominated by the diatom Skeletonema costatum, chl a samples from undiluted and $50 \%$ diluted plankton turned out to be partly phaeophytinized before acid was added to the acetone extracts. According to Suzuki \& Fujita (1986), spontaneous phaeophytinization of chlorophyll in cell concentrates may be due to the acidity of the cell sap in this species. We did not see this effect in the more diluted samples, probably because there was sufficient carbonate buffering capacity in the seawater left on the filters to neutralize the cell sap. We therefore could recalculate all chlorophyll values in the May experiment from the readings after acidification, using a factor derived from the diluted samples.

Results of the experiments are reported in terms of apparent specific growth rate (Landry \& Hassett 1982) as a function of the dimensionless dilution factor $x$ (where $x=1$ corresponds to an undiluted sample and $x$ $=0$ to infinite dilution). If we denote algal biomass at the dilution level $x$ at time $t$ by $C(x, t)$, the apparent specific growth rate $m(x)$ at dilution $x$ can then be written as

$$
m(x)=\frac{1}{t} \ln \left[\frac{C(x, t)}{C(x, 0)}\right)
$$

Mean chlorophyll concentrations at the beginning $(n=6)$ and end $(n=4)$ of incubation were used to calculate the apparent specific growth rate from Eq. (1). Each experiment gave apparent growth rates in 3 dilu- tion gradients denoted by $m_{+\mathrm{N}+\mathrm{P}}(x), m_{-\mathrm{N}}(x)$, and $m_{-\mathrm{P}}(x)$, corresponding respectively to combined $\mathrm{N}$ and $\mathrm{P}$ enrichment, $\mathrm{P}$ enrichment alone, and $\mathrm{N}$ enrichment alone.

Estimation of grazing-corrected mean growth rates. The rate of change in algal biomass is determined by the balance between growth and loss. Algal growth is expected to be a first-order process in algal biomass equal to $\mu C$, where $\mu$ is the specific growth rate $\left(\mathrm{d}^{-1}\right)$. Under full nutrient enrichment it is reasonable to assume that the specific growth rate will be constant (and equal to the maximum growth rate possible under the prevailing physical conditions). In the selectively enriched treatments, the assumption of a constant rate is invalidated by the known fact that instantaneous growth rates decline as internal and external nutrient pools become depleted (Goldman \& Glibert 1983, Turpin 1988, Harrison et al. 1989), and eventually reach zero. Under such conditions $\mu$ cannot be expected to be constant either with time or with dilution, and is therefore denoted as $\mu(x, t)$.

We may assume grazing to be the only densitydependent loss process during incubation. We further assume that grazing is unsaturated at all dilution levels, that grazer abundance is reduced by a factor $x$ but is otherwise unaffected by dilution, and that there is no grazing threshold (Landry \& Hassett 1982, Gallegos 1989). Under these assumptions, the loss rate is also a first-order process in algal biomass equal to $g \times C$, where $g$ is the phytoplankton biomass specific loss rate due to grazing $\left(\mathrm{d}^{-1}\right)$, often called the grazing coefficient. The grazing coefficient is really the product of grazer clearance rate and grazer abundance, of which the former is assumed to be constant and the latter to be proportional to $x$ alone.

Putting the component processes together, phytoplankton growth dynamics in diluted samples can be written as

$$
\frac{d C(x, t)}{d t}=[\mu(x, t)-g x] C(x, t)
$$

The analytical solution to the growth equation (Eq. 2) can be written as

$$
C(x, t)=C(x, 0) \exp \left[\int_{0}^{t} \mu(x, \tau) \mathrm{d} \tau-g x t\right)
$$

where $\tau$ is a formal integration variable. Eq. (3) can also be expressed in terms of the apparent growth rate at dilution level $x$, according to Eq. (1):

$$
m(x)=\frac{1}{t} \int_{0}^{t} \mu(x, \tau) d \tau-g x
$$

The integral term on the right-hand side of this equation can be interpreted as the time-weighted average 
of the growth rate over the duration of incubation. Introducing the mean growth rate $\tilde{\mu}(\mathrm{x})$ simplifies Eq. (4) to the following, which is a generalization of the original model of Landry \& Hassett (1982):

$$
m(x)=\tilde{\mu}(x)-g x
$$

If we assume that the grazing coefficient $g$ is unaffected by nutrient addition, we can obtain an independent estimate of this parameter from the dilution experiment with complete nutrient enrichment. The estimate is made by linear regression based on

$$
m_{+\mathrm{N}+\mathrm{P}}(\mathrm{x})=\mu_{\max }-g \mathrm{x}
$$

as described by Landry \& Hassett (1982). The mean growth rate $\tilde{\mu}(x)$ in experiments with incomplete nutrient enrichment can then be estimated from the observed apparent growth rate according to Eq. (5) as

$$
\tilde{\mu}_{-Y}(X)=m_{-Y}(X)+g X
$$

where $\mathrm{Y}$ is either $\mathrm{N}$ for experiments without $\mathrm{N}$ addition or $\mathrm{P}$ for experiments without $\mathrm{P}$ addition.

Estimation of contributing nutrient sources. In order to make a useful interpretation of the observed patterns in the estimated mean growth rate as a function of the dilution factor $x$, we will assume that $\tilde{\mu}(x)$ can be expressed in terms of a potential production, or potential growth increment, $\Delta C(x, t)$; that is,

$$
\tilde{\mu}(x)=\frac{1}{t} \ln \left(\frac{C(x, 0)+\Delta C(x, t)}{C(x, 0)}\right)
$$

We can identify 3 main sources of mineral nutrients to support growth during incubation: (1) dissolved nutrients present in the original water sample at the start of incubation $;$ (2) nutrients stored internally in the algae at the start of incubation; and (3) nutrients supplied by recycling through grazers. In this context we consider recycling to be the combined effect of excretion, egestion, and 'sloppy feeding'. The fourth major nutrient supply of importance to natural phytoplankton, namely diffusion and advection processes, is obviously excluded from bottle incubations.

Assume now that the potential biomass increment in the undiluted sample, $\Delta C(t)=\Delta C(1, t)$, can be separated into 3 components corresponding to these main sources - that is, the growth yield from the external nutrient pool, $\Delta C_{\mathrm{E}}(t)$; that from the internal nutrient stores, $\Delta C_{\mathrm{l}}(t)$; and that from recycling, $\Delta C_{\mathrm{R}}(t)$. The external nutrient pool will be unaffected by dilution, while the internal nutrient stores will be proportionally reduced by dilution. Dilution will reduce both the grazers and their food source by a factor $x$. The condition of constant clearance rate implies that the amount of phytoplankton consumed by the grazers will be proportional to $x^{2}$. If we assume that the amount of recycled nutrient is again proportional to the amount of food consumed, we can set up the following expression for the potential growth yield as a function of dilution:

$$
\Delta C(x, t)=\Delta C_{\mathrm{R}}(t) x^{2}+\Delta C_{\mathrm{I}}(t) \mathrm{x}+\Delta C_{\mathrm{E}}(t)
$$

The arguments leading to the quadratic dependence on dilution will probably be strictly valid for very short incubations only. If growth rate is declining during the incubation, one would expect also the nutrient content of the algae to decline. As the recycling rate of grazers is dependent on the nutrient content of their food (Olsen \& Østgaard 1985), one can easily imagine much more complicated relationships. Considering the quantity and quality of data that is normally obtainable, Eq. (9) is the farthest we dare go in model development for this kind of experiment.

Accepting Eq. (9) as a reasonable approximation to the potential growth yield as a function of dilution and noticing that the initial biomass in each dilution experiment will obviously be identical to the biomass of the original, undiluted water sample, reduced by a factor $x$, i. e. $C(x, 0)=x C(1,0)-$ Eqs. (8) and (9) can be combined to give

$$
\tilde{\mu}(x)=\frac{1}{t} \ln \left[1+\frac{\Delta C_{\mathrm{R}}(t) x^{2}+\Delta C_{\mathrm{I}}(t) x+\Delta C_{\mathrm{E}}(t)}{x C(1,0)}\right]
$$

If we introduce the potential production coefficient due to nutrient source $\mathrm{Z}$, denoted by $K_{\mathrm{z}}=\Delta C_{\mathrm{z}}(\mathrm{x}, t) / C(1,0)$, we can re-express this equation in the 3 parameters $K_{\mathrm{R}}$, $K_{\mathrm{I}}$, and $K_{\mathrm{E}}$, which are related to the relative yields of recycled, internal, and external nutrients, respectively. This gives the final expression for the expected relationship between the average growth rate $\tilde{\mu}(x)$ and the dilution factor $\mathrm{x}$ :

$$
\tilde{\mu}(x)=\frac{1}{t} \ln \left(1+K_{\mathrm{R}} x+K_{\mathrm{I}}+K_{\mathrm{E}} X^{-1}\right)
$$

The features of Eq. (11) are depicted in Fig. 1, showing the most general case where all three sources contribute to the mean growth rate. In this case the mean growth rate characteristically is a convex function of $x$, due to the importance of the external pool at high dilution and of recycling at low dilution. One would expect $\tilde{\mu}(\mathrm{x})$ to be constant below the dilution level which allows the external pool to support growth at the maximum attainable rate. This will only be possible if the external nutrient concentration is high enough to avoid transport limitation of the growth process. If there is no recycling, $\bar{\mu}(x)$ will be a monotonically decreasing function of $x$, since dilution will increase the amount of external nutrient available to each unit of algal biomass. On the other hand, if there is no external pool, $\tilde{\mu}(x)$ will be a monotonically increasing function of $x$ due to the dilution effect on recycling. For the simplest case where growth is sup- 


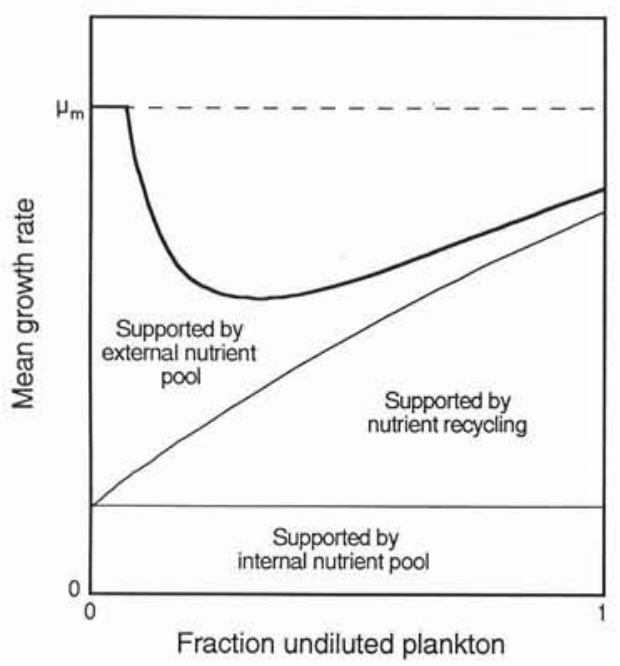

Fig. 1. Model calculation using arbitrary values of $K_{\mathrm{E}}, K_{1}$, and $K_{\mathrm{R}}$ (Eq. 11), showing the contributions of external and internal nutrient pools, as well as of nutrient remineralization, to the realized mean growth rate (heavy continous line). $\mu_{\mathrm{m}}$ : maximum growth rate

ported by internal storage alone, $\tilde{\mu}(x)$ will be independent of $x$.

The parameters $K_{\mathrm{R}}, K_{\mathrm{I}}$, and $K_{\mathrm{E}}$ can be estimated by fitting Eq. (11) to estimates of $\tilde{\mu}(x)$ by some nonlinear regression method. Alternatively, by taking antilogs on both sides of Eq. (11), we obtain the following expression:

$$
\exp [\tilde{\mu}(x) t]-1=K_{\mathrm{R}} x+K_{\mathrm{I}}+K_{\mathrm{E}} x^{-1}
$$

where the left-hand side is a function of $\tilde{\mu}(x)$ alone, and the right-hand side is linear in the unknown parameters $K_{\mathrm{R}}, K_{\mathrm{I}}$, and $K_{\mathrm{E}}$. This means that we can estimate the parameters $K_{\mathrm{R}}, K_{\mathrm{l}}$, and $K_{\mathrm{E}}$ by multiple linear regression, with $x$ and $x^{-1}$ as independent variables and $\exp [\tilde{\mu}(x) t]-1$ as the dependent variable. We chose this latter procedure.

The parameters $K_{\mathrm{R}}, K_{\mathrm{I}}$ and $K_{\mathrm{E}}$ are all by definition non-negative, but it is easy to imagine situations where one or more of them can be 0 , or at least insignificant compared to the others. Although the nonlinear transformation might introduce some bias in the estimated parameters, we believe that this is outweighed by the power of stepwise multiple regression in excluding insignificant parameters.

\section{RESULTS}

\section{Water column conditions}

The distribution with depth of density $\left(\sigma_{t}\right), \mathrm{PO}_{4}$, and $\mathrm{NO}_{3}$ is shown in Fig. 2. The density profiles show a pycnocline extending downwards mostly from the 5 to

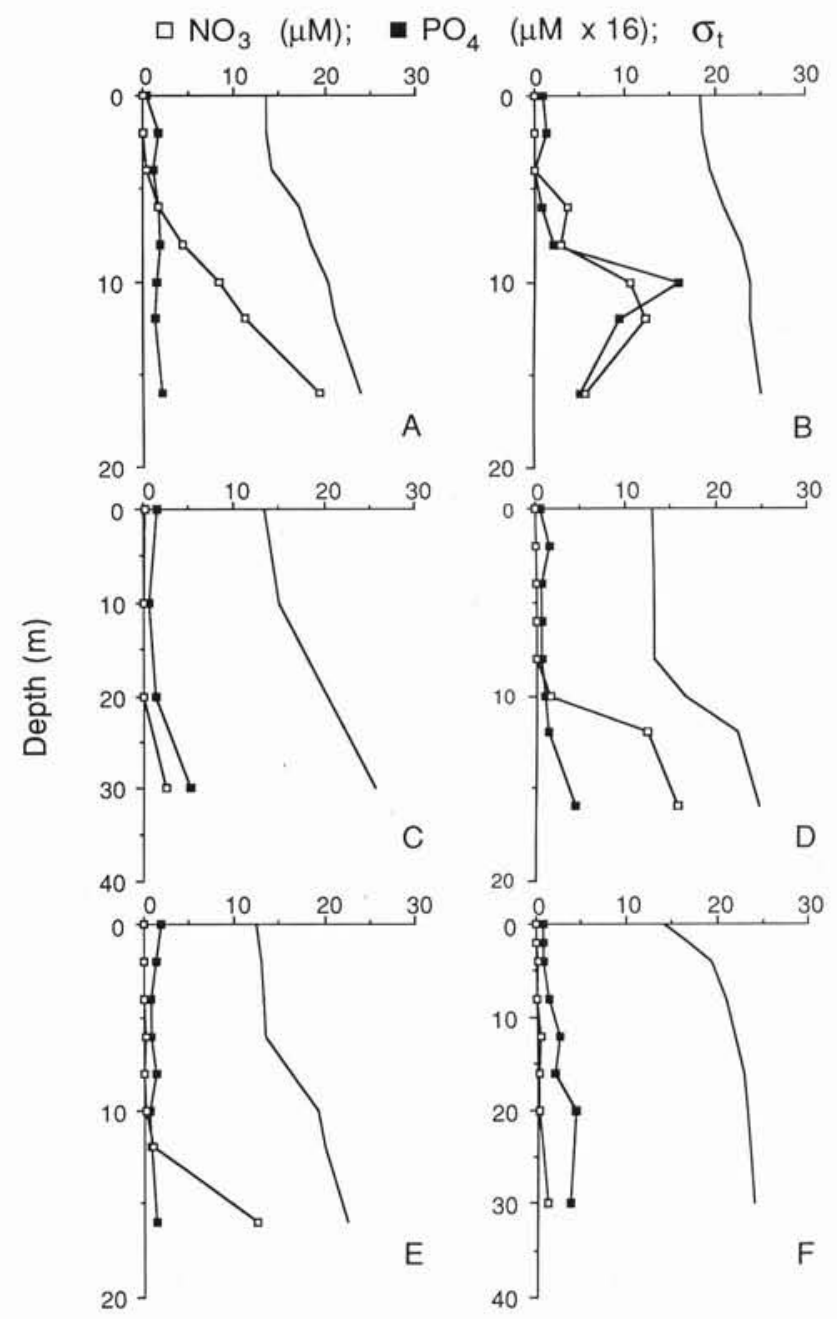

Fig. 2. Distribution with depth of orthophosphate, nitrate, and density $\left(\sigma_{t}\right.$ : continuous line) on the 6 sampling dates. (A) 25 May, (B) 21 June, (C) 6 July, (D) 7 July, (E) 8 August, (F) 9 August. (C) and (F) are from the outer fjord, the others from the inner fjord

$10 \mathrm{~m}$ depth level, which is typical for the Oslofjord in summer. Nutrient concentrations at the experimental sampling depths together with concentrations of $\mathrm{chl} a$ are given in Table 1. Nutrient levels in the upper mixed layer were close to the lowest ever measured in the fjord. In the inner fjord in May, July and August, a downward displacement of the phosphacline relative to the nitracline was noted (Fig. 2a, d, e). The same phenomenon was seen in summer 1986 (Paasche \& Erga 1988). Chlorophyll concentrations (1 to $7 \mu \mathrm{g}$ chl a $1^{-1}$ ) were similar to those observed in previous years (Paasche \& Erga 1988).

Plankton species composition is shown in Table 2. The bulk of the biomass (in chl a units) in May consisted of the diatom Skeletonema costatum; in June, of flagellates belonging to the Prymnesiophyceae and 
Table 1. Temperature, salinity, dissolved $\mathrm{P}$ and $\mathrm{N}$ nutrients, and chlorophyll a concentrations at the experimental sampling depths in the inner and outer parts of the Oslofjord, Norway

\begin{tabular}{|c|c|c|c|c|c|c|c|c|}
\hline Date & Station & $\begin{array}{l}\text { Depth } \\
\text { (m) }\end{array}$ & $\begin{array}{c}\text { Temp. } \\
\left({ }^{\circ} \mathrm{C}\right)\end{array}$ & $\begin{array}{c}\text { Salinity } \\
(\% 0)\end{array}$ & $\begin{array}{l}\mathrm{PO}_{4} \\
(\mu \mathrm{M})\end{array}$ & $\begin{array}{l}\mathrm{NO}_{3} \\
(\mu \mathrm{M})\end{array}$ & $\begin{array}{l}\mathrm{NH}_{4} \\
(\mu \mathrm{M})\end{array}$ & $\begin{array}{c}\text { Chl } a \\
\left(\mu \mathrm{g} \mathrm{I}^{-1}\right)\end{array}$ \\
\hline 25 May & Inner & 2 & 13.62 & 18.34 & 0.11 & 0.00 & 0.26 & 5.19 \\
\hline 21 Jun & Inner & 2 & 19.93 & 26.61 & 0.08 & 0.00 & 0.25 & 2.92 \\
\hline $6 \mathrm{Jul}$ & Outer & 1 & 19.85 & 19.61 & 0.10 & 0.16 & 0.06 & 3.69 \\
\hline $7 \mathrm{Jul}$ & Inner & 2 & 19.43 & 19.02 & 0.09 & 0.00 & 0.14 & 7.30 \\
\hline $8 \mathrm{Aug}$ & Inner & 2 & 18.74 & 18.85 & 0.09 & 0.00 & 0.33 & 5.70 \\
\hline 9 Aug & Outer & 4 & 17.44 & 26.68 & 0.05 & 0.10 & 0.48 & 1.14 \\
\hline
\end{tabular}

Prasinophyceae; in July, of the diatom Rhizosolenia fragilissima; and in August, of large dinoflagellates (Ceratium spp.) in the inner fjord, and smaller dinoflagellates and other flagellates in the outer fjord.

\section{Maximum growth rates and grazing coefficients}

Fig. 3 shows apparent growth rates from the complete nutrient enrichment experiments $\left[m_{+\mathrm{N}+\mathrm{P}}(x)\right.$, calculated from Eq. (1)] as a function of the fraction undiluted plankton $(x)$. Polynomial regression revealed no significant quadratic or higher terms in $\mathrm{x}$ on any of the 6 dates, leading to the acceptance of the linear model (Eq. 6) for all these experiments. Maximum growth rates $\left(\mu_{\max }\right)$ and grazing coefficients $(g)$, obtained from linear regression according to Eq. (6), are shown in Table 3. Maximum growth rates ranged from $1.6 \mathrm{~d}^{-1}$ in the Skeletonema costatum community of late May down to $0.41 \mathrm{~d}^{-1}$ in the Ceratium spp. dominated plankton of early August. The estimates were quite precise, with a relative standard deviation of less than $8 \%$ in all 6 cases. These same 2 experiments yielded the extremes in estimated grazing coefficients, ranging from $1.08 \mathrm{~d}^{-1}$ in the $S$. costatum bloom down to $0.02 \mathrm{~d}^{-1}$ in the Ceratium spp. community. These estimates had lower precision than did the maximum growth rates, but with the exception of 8 August, all were significantly different from 0 on a $95 \%$ confidence level. A

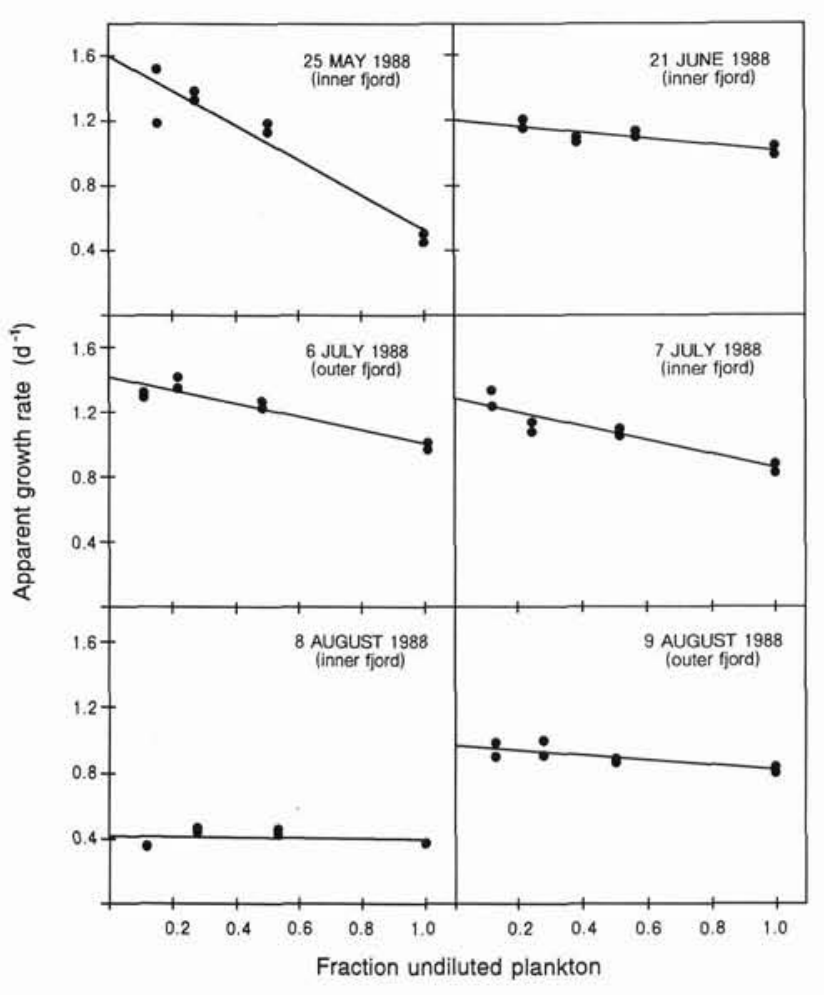

Fig. 3. Apparent growth rate as a function of the dilution factor in experiments with complete $\mathrm{N}$ and $\mathrm{P}$ enrichment. The straight lines are least squares fits according to Landry \& Hassett (1982)

Table 2. Relative distribution (\%) of chlorophyll biomass in the inner and outer parts of the Oslofjord, Norway

\begin{tabular}{|c|c|c|c|c|c|c|}
\hline Species & $\begin{array}{l}25 \text { May } \\
\text { Inner }\end{array}$ & $\begin{array}{l}21 \text { Jun } \\
\text { Inner }\end{array}$ & $\begin{array}{l}6 \text { Jul } \\
\text { Outer }\end{array}$ & $\begin{array}{l}7 \mathrm{Jul} \\
\text { Inner }\end{array}$ & $\begin{array}{l}8 \text { Aug } \\
\text { Inner }\end{array}$ & $\begin{array}{l}9 \text { Aug } \\
\text { Outer }\end{array}$ \\
\hline Skeletonema costatum & 91 & 4 & 1 & 0 & 0 & 0 \\
\hline Rhizosolenia fragilissima & 0 & 2 & 69 & 82 & 11 & 3 \\
\hline Other diatoms & 0 & 0 & 8 & 0 & 11 & 1 \\
\hline Ceratium spp. & 0 & 0 & 0 & 2 & 49 & 9 \\
\hline Prorocentrum spp. & 0 & 0 & 0 & 1 & 17 & 17 \\
\hline Other dinoflagellates & 8 & 0 & 1 & 10 & 2 & 12 \\
\hline Other flagellates & 0 & 94 & 21 & 4 & 11 & 58 \\
\hline Total & 100 & 100 & 100 & 100 & 100 & 100 \\
\hline
\end{tabular}


Table 3. Maximum growth rates $\left(\mu_{\max } ; \mathrm{d}^{-1}\right) \pm \mathrm{SD}$, and grazing coefficients $\left(g ; \mathrm{d}^{-1}\right) \pm \mathrm{SD}$, estimated by linear regression from experiments with excess $\mathrm{N}$ and $\mathrm{P}$, according to the model of Eq. (6). $R^{2}$ : coefficient of determination for the regression; $n$ : number of observation

\begin{tabular}{|lcccc|}
\hline Date & Station & $\mu_{\max }$ & $g$ & $\mathrm{R}^{2}(\mathrm{n})$ \\
\hline 25 May & Inner & $1.60 \pm 0.08$ & $1.08 \pm 0.14$ & $0.91(8)$ \\
21 Jun & Inner & $1.22 \pm 0.03$ & $0.19 \pm 0.05$ & $0.75(8)$ \\
6 Jul & Outer & $1.42 \pm 0.04$ & $0.41 \pm 0.06$ & $0.88(8)$ \\
7 Jul & Inner & $1.29 \pm 0.04$ & $0.43 \pm 0.07$ & $0.87(8)$ \\
8 Aug & Inner & $0.41 \pm 0.03$ & $0.02 \pm 0.06$ & $0.02(8)$ \\
9 Aug & Outer & $0.97 \pm 0.03$ & $0.15 \pm 0.04$ & $0.65(8)$ \\
\hline
\end{tabular}

closer evaluation of the grazing data will be presented elsewhere (Schartau \& Paasche unpubl.)

\section{Contributing $\mathbf{N}$ and $\mathrm{P}$ sources}

Compared to the fully enriched treatment, the experiments with partial enrichment $(-\mathrm{N}$ or $-\mathrm{P})$ exhibited a drastic reduction in apparent growth rate, which is illustrated by the observations from the undiluted samples in Table 4. Net growth rates were negative or close to 0 for at least one treatment on all dates except 9 August.

In order to correct for direct grazing effects, the estimated grazing coefficients (Table 3 ) were used to convert apparent growth rates from the experiments with partial enrichment $\left[m_{-N}(x)\right.$ and $\left.m_{-P}(x)\right]$ to grazing-corrected mean growth rates $\tilde{\mu}(\mathrm{x})$, according to Eq. (7). Mean growth rates as functions of the fraction undiluted plankton $(x)$ are shown in Figs. $4 \& 5$ for experiments without $\mathrm{N}$ and $\mathrm{P}$ addition, respectively. Relative nutrient pools $\left(K_{\mathrm{R}}, K_{\mathrm{I}}\right.$, and $\left.K_{\mathrm{E}}\right)$ were estimated from the linearized equation (Eq. 12) by stepwise multiple regression (forward selection procedure, $F=4$ to enter the regression) on mean growth rates transformed by $\exp [\tilde{\mu}(x) t]-1$, with $x$ and $x^{-1}$ as independent variables. Parameter estimates for the variables retained in the final regression are shown in Tables 5 ( $-\mathrm{N}$ experiments) and $6(-\mathrm{P}$ experiments), and the fitted lines are also shown in Figs. $4 \& 5$.

Figs. 4 \& 5 show a wide variety of relationships between the mean growth rate and the dilution factor, ranging in complexity from the $-\mathrm{P}$ experiments on 6 and 7 July, which had contributions from all 3 sources, to the $-\mathrm{P}$ experiments on 8 and 9 August, in which the mean growth rates were supported by internal stores alone (Fig. 5). Significant contributions from recycling were found in both the $-\mathrm{N}$ and $-\mathrm{P}$ experiments on the 3 dates having the highest grazing intensities (25 May, 6 July, 7 July; Table 3). Significant internal stores were identified for all the $-\mathrm{P}$ experiments (Table 6), but for
Table 4. Apparent growth rates $\left(\mu_{;} \mathrm{d}^{-1}\right)$ in undiluted samples where $\mathrm{N}$ or $\mathrm{P}$ was omitted from the enrichment

\begin{tabular}{|llrc|}
\hline Date & Station & No N added & No P added \\
\hline 25 May & Inner & -0.43 & -0.43 \\
21 Jun & Inner & 0.01 & 0.40 \\
6 Jul & Outer & -0.08 & 0.21 \\
7 Jul & Inner & -0.20 & -0.01 \\
8 Aug & Inner & 0.07 & 0.21 \\
9 Aug & Outer & 0.48 & 0.53 \\
\hline
\end{tabular}

only $2-\mathrm{N}$ experiments (from August; Table 5). On the other hand, there was a tendency for greater importance of external sources in the $-\mathrm{N}$ experiments than in the $-\mathrm{P}$ experiments (Tables 5 \& 6).

Fig. 6 shows the observed mean growth rates plotted against values predicted from Eq. (11) with the estimated parameters from Tables $5 \& 6$. The clustering of points around the $1: 1$ line indicates that any bias introduced in the transformation (Eq. 12) should be small. Due to the chosen replication scheme, the effective number of degrees of freedom is low (close to 1) in some of the fits where all contributing factors were significant. Fig. 6 should therefore be interpreted not as

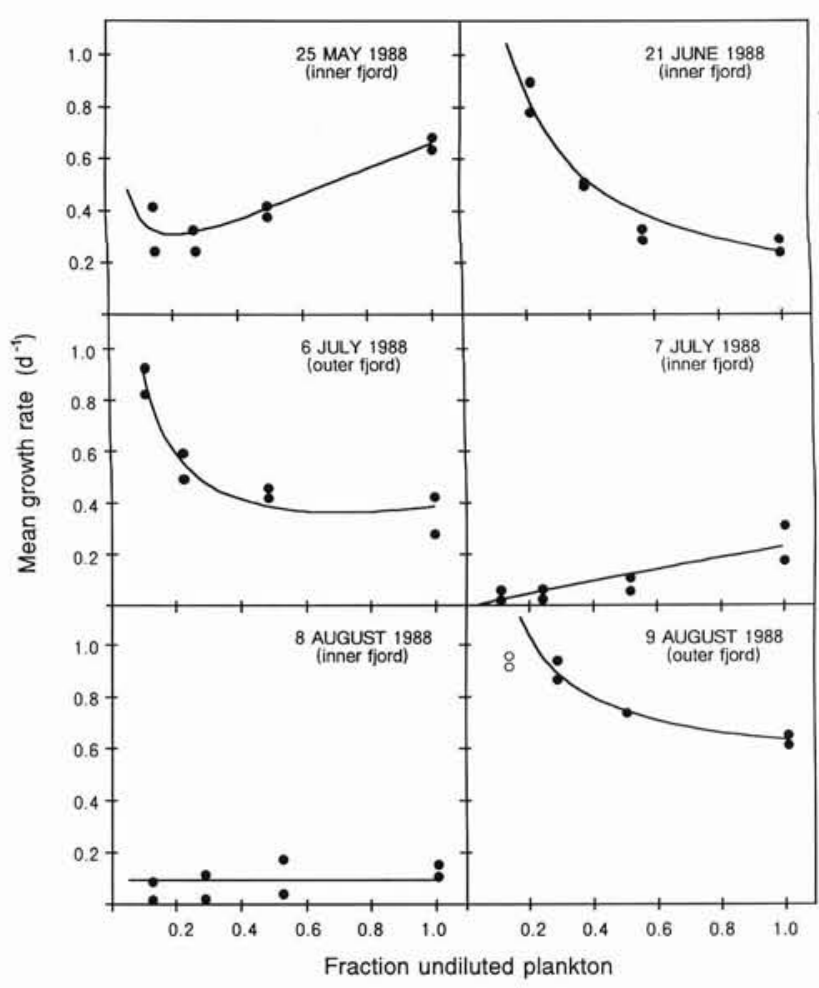

Fig. 4. Mean growth rate as a function of the dilution factor in experiments with no $\mathrm{N}$ enrichment. The curves are given by the model of Eq. (11), with parameters determined by stepwise multiple regression on the transformed equation (Eq. 12). Open symbols on 9 August represent measurements that were not included in the calculation 


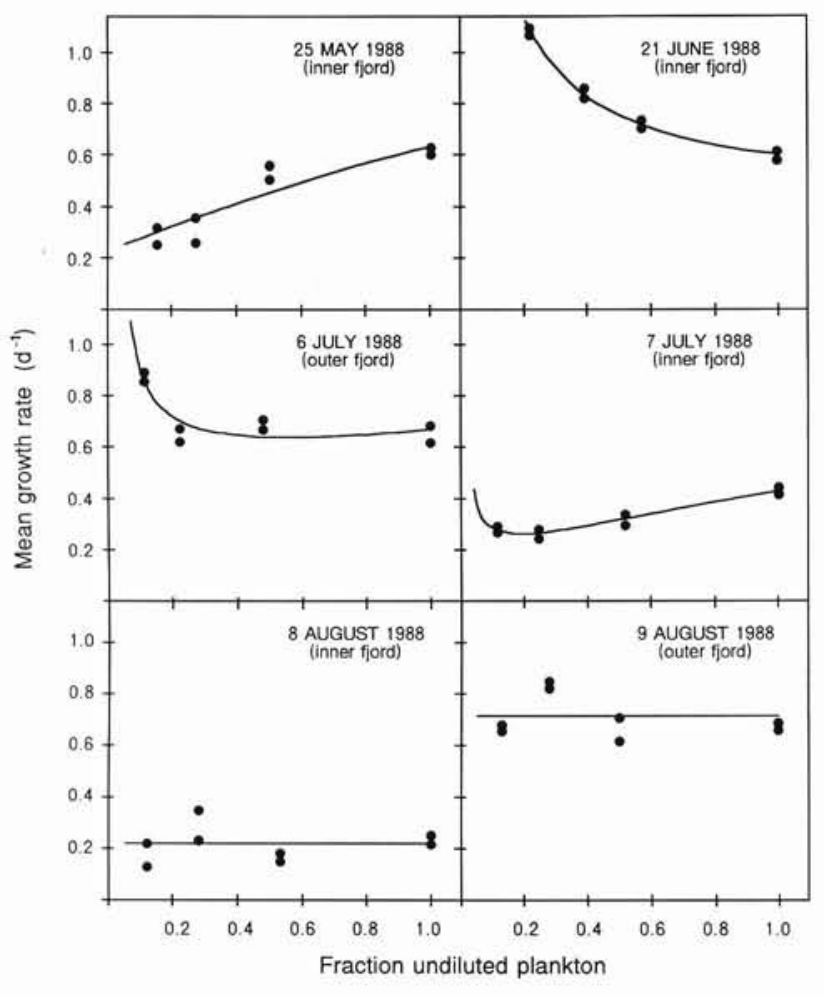

Fig. 5. Mean growth rate as a function of the dilution factor in experiments with no $\mathrm{P}$ enrichment. The curves are given by the model of Eq. (11), with parameters determined by stepwise multiple regression on the transformed equation (Eq. 12)

a general statement of the adequacy of Eq. (11), but as an indication that Eq. (11) exhausts the available information in the present data set.

In order to compare more easily the N- and P-limited experiments, the partitioning of the potential production into components supported by recycling and internal/external pools are shown graphically in Fig. 7 . The potential production is calculated by multiplying the production coefficients in Tables 5 and 6 by the initial biomasses $\left[C(1,0), \mu \mathrm{g} \mathrm{chl} \mathrm{a} 1^{-1}\right]$ from Table 1 .

\section{Plankton dynamics on individual sampling dates}

25 May. This Skeletonema costatum bloom situation (Table 2) showed the highest grazing intensity of all the experiments $\left(g=1.08 \pm 0.14 \mathrm{~d}^{-1}\right.$; Table 3$)$. The estimated maximum growth rate of $1.60 \pm 0.08 \mathrm{~d}^{-1}$ corresponds well with a reported growth rate of $1.7 \mathrm{~d}^{-1}$ at $20^{\circ} \mathrm{C}$ in a strain of $S$. costatum isolated from the Oslofjord (Paasche 1973). Table 4 shows that, in the undiluted samples, more than half of the grazing loss was compensated by growth, giving a net growth rate of $-0.43 \mathrm{~d}^{-1}$ in both the $-\mathrm{N}$ and $-\mathrm{P}$ treatments. The situation may be described as one in which a $S$. costatum population was subject to intense grazing, but in which the grazing effect was largely offset by nutrient recycling from the grazers (Fig. 7). The small external $\mathrm{N}$ pool compared to the substantial internal $\mathrm{P}$ pool was to a considerable degree compensated by a higher supply of recycled $N$, leading to a situation where $\mathrm{N}$ and $\mathrm{P}$ were equally limiting.

21 June. The $-\mathrm{N}$ treatment gave the lowest growth rate in the undiluted samples $\left(0.01 \mathrm{~d}^{-1}\right.$; Table 4$)$, indicating a close balance between growth and grazing loss in this flagellate plankton community (Table 2). Despite the near-zero analytical values of dissolved nutrients (Table 1), significant external pools of both $\mathrm{N}$ and $\mathrm{P}$ were identified (Fig. 7). Although the external $\mathrm{N}$ and $\mathrm{P}$ pools were nearly equal, the additional presence of an internal store of P (Fig. 7) suggests that the flagellate plankton growing on 21 June was running close to $\mathrm{N}$ limitation. The estimation procedure was unable to identify any significant contribution from nutrient recycling, indicating that this process was of minor importance in compensating for the estimated grazing loss rate of $0.19 \pm 0.05 \mathrm{~d}^{-1}$.

6 and 7 July. These 2 experiments offer an interesting comparison between the inner and outer fjord. The plankton was dominated by the diatom Rhizosolenia fragilissima in both instances (Table 2). Hydrography and nutrient concentrations were very similar (Table 1 ).

Table 5. Potential production coefficients $\pm \mathrm{SD}$, due to recycled $\mathrm{N}\left(K_{\mathrm{R}}\right)$, internal $\mathrm{N}$ stores $\left(K_{\mathrm{l}}\right)$, and external $\mathrm{N}$ pool $\left(K_{\mathrm{E}}\right)$, estimated by stepwise multiple linear regression from the experiments without $\mathrm{N}$ addition, according to the model of Eq. (12). $\mathrm{R}^{2}$ : coefficient of determination for the regression; n: number of observations. Only coefficients for variables retained in the final regression equation are shown

\begin{tabular}{|c|c|c|c|c|c|}
\hline Date & Station & $K_{\mathrm{R}}$ & $K_{\mathrm{I}}$ & $K_{\mathrm{E}}$ & $\mathrm{R}^{2}(\mathrm{n})$ \\
\hline 25 May & Inner & $0.88 \pm 0.05$ & & $0.04 \pm 0.01$ & $0.99(8)$ \\
\hline 21 Jun & Inner & & & $0.27 \pm 0.01$ & 0.99 (8) \\
\hline $6 \mathrm{Jul}$ & Outer & $0.32 \pm 0.08$ & & $0.15 \pm 0.01$ & $0.99(8)$ \\
\hline $7 \mathrm{Jul}$ & Inner & $0.26 \pm 0.04$ & & & $0.87(8)$ \\
\hline $8 \mathrm{Aug}$ & Inner & & $0.09 \pm 0.02$ & & $0.00(8)$ \\
\hline 9 Aug & Outer & & $0.65 \pm 0.09$ & $0.22 \pm 0.04$ & $0.93(6)^{\mathrm{a}}$ \\
\hline
\end{tabular}


Table 6. Potential production coefficients $\pm \mathrm{SD}$, due to recycled $\mathrm{P}\left(K_{\mathrm{R}}\right)$, internal P stores $\left(K_{\mathrm{I}}\right)$, and external P pool $\left(K_{\mathrm{E}}\right)$, estimated by stepwise multiple linear regression from the experiments without $\mathrm{P}$ addition, according to the model of Eq. (12). $\mathrm{R}^{2}$ : coefficient of determination for the regression; $\mathrm{n}$ : number of observations. Only coefficients for variables retained in the final regression equation are shown

\begin{tabular}{|llccrc}
\hline Date & Station & $K_{\mathrm{R}}$ & $K_{\mathrm{I}}$ & $K_{\mathrm{E}}$ & $\mathrm{R}^{2}(\mathrm{n})$ \\
\hline $25 \mathrm{May}$ & Inner & $0.64 \pm 0.11$ & $0.26 \pm 0.07$ & $0.84(8)$ \\
21 Jun & Inner & & $0.49 \pm 0.02$ & $0.32 \pm 0.01$ & $1.00(8)$ \\
$6 \mathrm{Jul}$ & Outer & $0.29 \pm 0.11$ & $0.57 \pm 0.18$ & $0.08 \pm 0.02$ & $0.81(8)$ \\
$7 \mathrm{Jul}$ & Inner & $0.36 \pm 0.04$ & $0.17 \pm 0.04$ & $0.01 \pm 0.005$ & $0.96(8)$ \\
$8 \mathrm{Aug}$ & Inner & & $0.25 \pm 0.03$ & $0.00(8)$ \\
$9 \mathrm{Aug}$ & Outer & & $1.04 \pm 0.06$ & $0.00(8)$ \\
\hline
\end{tabular}

Nutrient-saturated growth rates, as well as grazing rates, were also very similar (Table 3 ), whereas the standing stock of plankton was twice as great in the inner fjord (7 July experiment; Table 1). Paasche (1980) found a growth rate of $1.1 \mathrm{~d}^{-1}$ at $20^{\circ} \mathrm{C}$ in cultures of $R$. fragilissima isolated from the Oslofjord, which is in fair agreement with the present estimates of $1.42 \pm 0.04$ $\mathrm{d}^{-1}$ in the outer fjord and $1.29 \pm 0.04 \mathrm{~d}^{-1}$ in the inner fjord. The slightly higher growth rate in the outer fjord might be attributable to the higher fraction of presumably faster-growing flagellates at this station (Table 2). The $-\mathrm{N}$ treatments gave apparent growth rates that were lower than those for the $-\mathrm{P}$ treatments at both stations (Table 4). Fig. 7 shows that this difference was due mostly to the ample internal stores of $\mathrm{P}$, while contributions from recycled and external $\mathrm{N}$ and $\mathrm{P}$ were quite similar. Despite the 2-fold difference in biomass, combined supplies of $\mathrm{N}$ and $\mathrm{P}$ were nearly equal at the 2 stations. This indicates that the larger standing stocks developing in the inner fjord were under greater nutrient stress, in the sense that a temporary imbalance

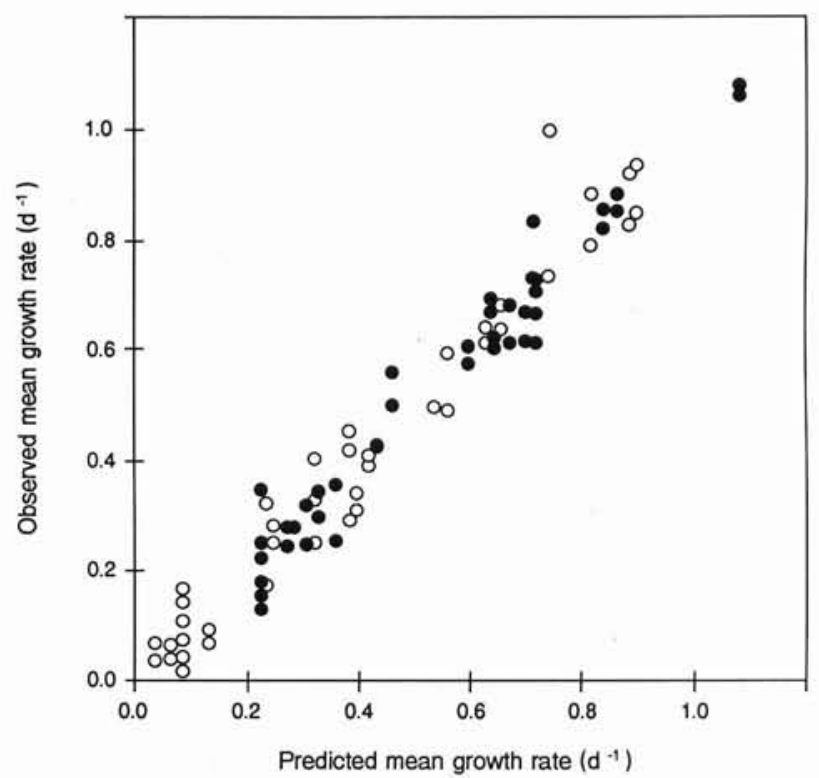

Fig. 6. Observed vs predicted mean growth rates in all 6 experiments. Open symbols: experiments with no $\mathrm{N}$ enrich-

ment; filled symbols: experiments with no P enrichment
Fig. 7. Estimated contributions of internal (filled bars) and external (hatched bars) nutrient pools, and of nutrient remineralization (open bars), to the potential increments in chlorophyll standing stocks during $24 \mathrm{~h}$ incubations in the experiments with no N (left) or P (right) enrichment
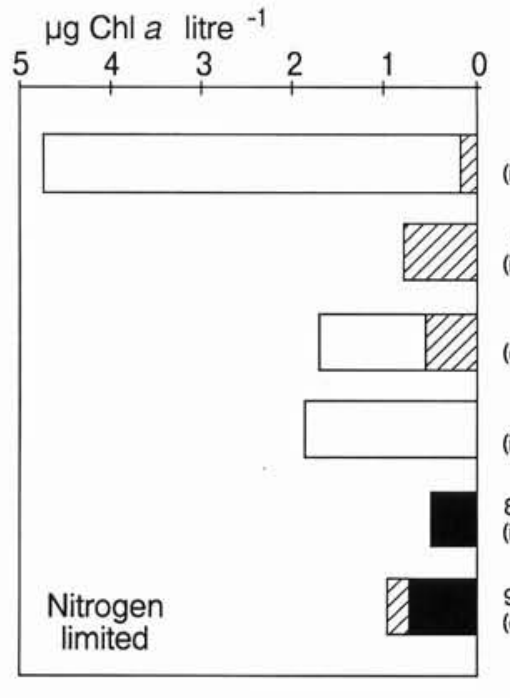

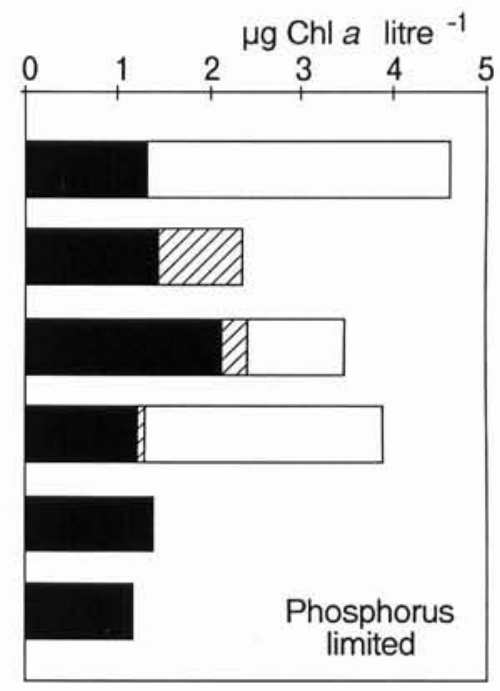


between nutrient supply and demand could occur more easily there.

8 August. The plankton, in which large Ceratium sp. cells were predominant on this date (Table 2), apparently was not grazed at all (Table 3 ). The relatively low maximum growth rate of $0.41 \pm 0.03 \mathrm{~d}^{-1}$ is comparable to laboratory measurements on strains of Ceratium spp. isolated from the Oslofjord by Nordli (1957), who reported growth rates of $0.25 \mathrm{~d}^{-1}$ at $20^{\circ} \mathrm{C}$. Net growth rates were low, although clearly positive, in both the undiluted $-\mathrm{N}$ and undiluted $-\mathrm{P}$ treatments (Table 4). The results suggested that no external $\mathrm{N}$ or $\mathrm{P}$ was available and that internal $\mathrm{N}$ pools were closer to exhaustion than were the intracellular $\mathrm{P}$ reserves (Fig. 7).

9 August. The plankton in the outer fjord differed from that in the inner by the predominance of smaller flagellates (Table 2) with a higher intrinsic growth rate (Table 3). The experiment, although marred by experimental scatter, showed that even moderate dilution $(x \leq 0.25)$ brought growth in the P-enriched samples up to the level of that in the complete $(+\mathrm{N}+\mathrm{P})$ enrichment. The lowest dilution level was therefore excluded from the analysis in the $-\mathrm{N}$ experiment (Fig. 4). Internal pools of both $\mathrm{N}$ and $\mathrm{P}$ were fairly large compared with the low biomass on this date, while no contribution from recycling could be identified (Fig. 7). This was the only date on which appreciable net growth was realized in the simultaneous absence of $\mathrm{N}$ or P enrichment (Table 4). Algal growth appeared to be supported entirely by internal reserves in the case of $\mathrm{P}$, and by internal as well as external reserves in the case of $\mathrm{N}$ (Fig. 7).

\section{DISCUSSION}

In the Landry \& Hassett (1982) type experiment, chl a is generally used as a measure of growth. The assumption is that chlorophyll increases in proportion to algal biomass, so that the measured net chlorophyll increase integrates the effects of light, nutrients, etc., on algal proliferation. This assumption has been criticized by Burkill et al. (1987), who pointed out that minor components of the algal community may grow (and also be grazed) much faster than is indicated by bulk chlorophyll measurements. We do not believe this is an important objection in our case, as the bulk growth rates we found were compatible with several independent measurements from Oslofjord strains of the dominant species grown in culture (see the preceding section).

Furthermore, the correspondence between our estimates and independent measurements of nutrientsaturated growth rates from strains of the same species indicates that dilution-independent mortality due to containment per se (Venrick et al. 1977) probably was of minor importance in our experiments. In our experience, the sampling and incubation equipment (pumping gear and incubation bottles) used here is nontoxic to plankton algae. Because our experiments were of the 'all minus one' design, any detrimental effects on sensitive organisms resulting from nutrient enrichment (Gifford 1988) should apply to all incubations, and therefore should not invalidate comparisons between treatments.

In the analysis of effects of nutrient addition, it is implicitly assumed that the aliquots of filtered and unfiltered seawater are chemically identical with respect to dissolved nutrients. If organisms were to break up on the filter, nutrients from the cell sap would be added to the dissolved nutrient pool in proportion to the fraction $1-x$ of filtered seawater (something that might possibly have been verified by chemical analysis). If the growth potential due to cell breakage under filtration is denoted by $\Delta C_{\mathrm{B}}$. Eq. (9) will be modified to

$$
\begin{gathered}
\Delta C(x, t)=\Delta C_{\mathrm{R}}(t) x^{2}+\Delta C_{\mathrm{I}}(t) x+\Delta C_{\mathrm{E}}(t)+ \\
\Delta C_{\mathrm{B}}(t)(1-x)
\end{gathered}
$$

leading to the following changes in Eq. (11):

$$
\tilde{\mu}(x)=\frac{1}{t} \ln \left(1+K_{\mathrm{R}} x+K_{\mathrm{I}}^{\prime}+K_{\mathrm{E}}^{\prime} x^{-1}\right)
$$

where $K_{\mathrm{I}}^{\prime}=K_{\mathrm{I}}-K_{\mathrm{B}}$ and $K_{\mathrm{E}}^{\prime}=K_{\mathrm{E}}+K_{\mathrm{B}}$. This shows that changes in the chemical composition of the filtrate will lead to underestimation of the internal pool and overestimation of the external pool, while neither the contribution from recycling nor the sum of the internal and external pools will be biased.

The Landry \& Hassett (1982) model rests on the assumption that all rate coefficients remain constant throughout the incubation period. The present generalization of this model has relaxed this restriction on the growth rate, which is allowed to vary with both time and dilution, while the invariance of the chlorophyll-specific grazing coefficient remains a crucial assumption behind the whole estimation procedure. Gallegos (1989) analyzed the consequences of several violations of the assumptions of constant grazing rates. His analysis showed that nonlinearities, in the form of thresholds or saturation effects in the functional response of the grazers, can usually be detected as nonlinearities in the apparent growth rate as a function of dilution (cf. Fig. 5C in Gallegos 1989). We were unable to detect any significant nonlinearities in the apparent growth rate as a function of dilution in any of our experiments with full nutrient enrichment. We are also assured by the fact that chlorophyll levels in the localities where Gallegos (1989) was able to demonstrate a saturating functional response were an order of magnitude higher than those found in the Oslofjord. As 
final biomasses were uniformly highest in the full enrichment experiments, we expect these indications of an unsaturated grazing response to carry over into the experiments with partial nutrient enrichment.

Gallegos (1989) showed by numerical experiments that if the grazers are assumed to change in abundance during the incubation, this will bias the estimated grazing coefficient in the sense that positive net growth will give an overestimate of the grazing in the initial community. Fig. 5A in Gallegos (1989) indicates that the slight nonlinearity due to grazer growth in the apparent growth rate as a function of dilution will easily be masked by measurement errors. Thus we cannot make any inference regarding the validity of the assumption of constant grazer abundance based on the absence of nonlinearities in our measurements of apparent growth rates. The possibility of bias due to grazer growth affects dilution methods in general, and can only be controlled by measuring grazer biomasses and regressing apparent growth rates against grazer density, as suggested by Landry et al. (1984).

The assumption of unchanging grazer abundances throughout incubation is equivalent to assuming that grazer net growth rates are close to 0 due to low growth efficiency and/or high mortality. Due to lower phytoplankton biomasses and possibly lower nutritional value of slower-growing algae in the partial enrichments, the growth conditions for the grazers might be expected to be inferior compared to those in the full enrichment experiments. It is therefore reasonable to expect that if the assumption of unchanging grazer biomasses is valid for the full enrichment experiments, it will also be so for the partial enrichments. On the other hand, if there is significant net growth in the grazer populations, this will introduce a potentially serious bias in our estimates which cannot be corrected without access to grazer abundance data.

The use of 2 replicate incubations at each dilution level in our experimental design enabled us to make an assessment of the precision of the apparent growth rate measurements. The residual mean square error from a 3-way ANOVA on growth rate by station, enrichment, and dilution level gives a standard deviation in the growth rate measurements of $0.055 \mathrm{~d}^{-1}$. From linear regression on the data shown in Fig. 6, we obtain a comparable estimate of the residual root mean square error of $0.057 \mathrm{~d}^{-1}$ in the model (Eq. 11) fitted to the mean growth rates. This suggests that the residual lack of fit in Eq. (11) is largely due to measurement noise, and that Eq. (11) is sufficient given the present level of measurement noise.

It must be emphasized that the adequacy of our present model (Eq. 11) is qualified by the constraints of the chosen experimental design: 4 dilution levels with 2 replicates each give in reality only 1 degree of free- dom in the extreme case when all 3 parameters are significant. This is certainly not enough to constitute a proof of the validity of the simplifying assumptions behind Eq. (11). Only future experiments with more dilution levels and higher precision in growth rate measurements can show if further refinements to Eq. (11) are needed.

If we assume that the measurement errors in the initial and final chlorophyll values are uncorrelated, we can use first-order variance propagation analysis to approximate the variance component due to chlorophyll measurement errors alone in the apparent growth rates estimated from Eq. (1). If we denote the variances of the chlorophyll measurements and apparent growth rates by $S_{c}^{2}$ and $S_{m}^{2}$, respectively, we have the following expression:

$$
S_{m}^{2}(x, t)=\left[\frac{\partial m(x)}{\partial C(x, t)}\right]^{2} S_{c}^{2}(x, t)+\left(\frac{\partial m(x)}{\partial C(x, 0)}\right)^{2} S_{c}^{2}(x, 0)
$$

Substituting Eq. (1) for $m(x)$ in Eq. (13) and evaluating the partial differentials gives the final formulation of the approximate variance in the growth rate estimates as

$$
S_{m}^{2}(x, t)=\frac{1}{t^{2}}\left[\left[\frac{S_{c}(x, t)}{C(x, t)}\right]^{2}+\left[\frac{S_{c}(x, 0)}{C(x, 0)}\right]^{2}\right]
$$

Taking into consideration the wide dynamic range of fluorometric chlorophyll measurements, it is reasonable to assume that the observed relative measurement error of $3.1 \%$ is independent of chlorophyll concentration. The variances have to be weighted for the unequal number of replicates in the initial and final measurements, giving an approximate growth rate variance of $\left[(0.031 / 6)^{2}+(0.031 / 4)^{2}\right] \mathrm{d}^{-2}$, equivalent to a standard deviation in the apparent growth rates of $0.009 \mathrm{~d}^{-1}$. Comparing this standard deviation with the one estimated from replicate incubations $\left(0.055 \mathrm{~d}^{-1}\right)$ indicates that subsampling and incubation introduces errors in the growth rates much greater than those attributable to chlorophyll measurements alone.

The potential growth increments will be an unbiased measure of growth yields from the internal and external nutrient pools that are present at the start of incubation only if there is no recycling and if growth rate decreases to 0 by the end of incubation. Otherwise, the values shown in Fig. 7 will be minimum estimates for the biomass that can be produced from the nutrient initially present in the internal and external pools. The distinction between these initial nutrient pools and the continuous process of nutrient supply through recycling should be kept in mind.

External nutrient pools were of importance in 7 of the $12-\mathrm{N}$ and $-\mathrm{P}$ experiments, despite the uniformly low analytical values of dissolved nutrients (Table 1). This 
illustrates the difficulties associated with judging the presence or absence of nutrient stress based on nutrient concentrations alone. The analytical methods are imprecise at low concentrations. Moreover, not all potential substrates, such as $\mathrm{N}$ in urea (Kristiansen 1983) and perhaps in amino acids (Flynn \& Butler 1986), or P in the form of organic phosphate esters, are measured routinely. Also, the gradual mobilization of orthophosphate adsorbed to particles would constitute an analytically undetectable addition to the external P pool.

Chemical analyses of cultured marine diatoms and (dino)flagellates show that their cellular $\mathrm{N}$ and $\mathrm{P}$, as expressed e.g. per cell or per unit carbon, may vary several-fold in response to nutrient depletion (Harrison et al. 1977, Sakshaug et al. 1984, Miyata et al. 1986), testifying to their ability to grow on internal reserves. In nutrient-sufficient natural plankton, excess $\mathrm{N}$ or $\mathrm{P}$ has been shown to be present in the form of readily utilizable compounds such as amino acids (Dortch et al. 1985) and orthophosphate (Miyata \& Hattori 1986). According to the latter authors, orthophosphate can be stored in diatom plankton in inshore waters in quantities of up to ca $40 \%$ of total $\mathrm{P}$, so that complete utilization of this resource alone may suffice for a ca $70 \%$ increase in biomass. In general, the storage capacity in marine microalgae appears to be much greater for P than for N (Goldman \& McCarthy 1978, Miyata et. al. 1986, Turpin 1988). Internal P stores accounted for much of the growth potential in all our experiments, in absolute (Fig. 7) as well as relative terms (Tables 5 and 6), while internal $\mathrm{N}$ stores were insignificant or not demonstrable in 4 out of 6 cases.

Our data suggest that the intracellular reserves of $\mathrm{N}$ were closer to being depleted than were the P reserves, implying that physiological indicators (Yentsch et al. 1977, Healey \& Hendzel 1980, Myklestad \& Sakshaug 1983, Dortch et al. 1984, Glibert \& McCarthy 1984, Sakshaug \& Olsen 1986) would probably have pointed to $\mathrm{N}$ as the 'limiting' nutrient in the Oslofjord in summer 1988. In an investigation of the summer plankton in the inner Oslofjord in 1986, using physiological indicators, the general tendency was towards a deficiency in $\mathrm{P}$ rather than $\mathrm{N}$, although $\mathrm{N}$ limitation was indicated during a diatom bloom in July (Paasche \& Erga 1988). These observations are not necessarily in conflict, and are most likely indicative of the delicate balance between $\mathrm{N}$ and $\mathrm{P}$ limitation in summer situations in the Oslofjord, where small interannual variations in forcing variables such as wind, currents, and temperature might determine whether $\mathrm{N}$ or $\mathrm{P}$ will become limiting.

All the estimated mean growth rates in Figs. 4 \& 5 were significantly positive, indicating that in spite of $\mathrm{PO}_{4}$ and $\mathrm{NO}_{3}$ concentrations being close to the detection limit and $\mathrm{NH}_{4}$ concentrations usually $\leq 0.3 \mu \mathrm{M}$, there were always sufficient nutrients available in the system for several hours of further growth. Therefore, although internal stores generally were smaller for $\mathrm{N}$ than for $\mathrm{P}$, no strong and immediate limitation of algal growth rates by either nutrient seemed likely.

Previous work by Paasche \& Kristiansen (1982) has shown that recycling of $\mathrm{N}$ by the microzooplankton may sometimes, though not always, be important for the Oslofjord summer plankton. On the 3 dates where recycled nutrients contributed significantly to mean growth rate, our data suggest that $\mathrm{N}$ and $\mathrm{P}$ were supplied in nearly equal amounts relative to the demands of the phytoplankton. If we assume that the plankton community is close to equilibrium, this observation has several interesting implications. Firstly, if the supply of recycled nutrients is balanced with respect to $\mathrm{N}$ and $\mathrm{P}$, then the additional $\mathrm{P}$ in the internal stores must come from other sources, such as vertical advection and diffusion processes. In other words, the sources of 'new' and 'regenerated' production in the sense of Eppley \& Peterson (1979) should represent different supply ratios of $\mathrm{N}$ and $\mathrm{P}$. Secondly, if the food of the grazers is richer in $\mathrm{P}$ than in $\mathrm{N}$, as reflected by the presence of internal $\mathrm{P}$ stores, while the supply ratio of remineralized $\mathrm{N}$ and $\mathrm{P}$ is nearly optimal, then the grazers must retain more $\mathrm{P}$ than $\mathrm{N}$ from their food. This could mean that grazers and algae have different optimum N:P ratios for balanced growth.

Resource competition theory has proven to be a powerful tool in freshwater plankton ecology (Tilman 1980, Sommer 1983), and ranges of 'optimum' N:P ratios for marine and freshwater algae are overlapping (Rhee \& Gotham 1980, Sakshaug \& Olsen 1986), indicating that the basic premises for competition driven by $\mathrm{N}: \mathrm{P}$ supply ratios are the same in both environments. Zooplankton grazing is generally thought to represent a selection force towards fast-growing algal species or towards species with specialized predator defence. The possibility of different N:P supply ratios from remineralization as compared to other nutrient sources could imply a novel and potentially important coupling between predation and competition in plankton communities, where predation could also be a selection force on the basis of differences in $\mathrm{N}$ and $\mathrm{P}$ requirements between phytoplankton species.

Acknowledgements. We thank the crew of RV 'Trygve Braarud' for assistance during the cruises, and Sissel Brubak and Tone Jacobsen for excellent help with data collection and processing. We are grateful to Charles L. Gallegos, Dag O. Hessen, Michael R. Landry, John T. Lehman, Anne Lyche, and 2 anonymous reviewers for constructive criticism of the manuscript. This investigation was supported by The Council for Water Management Cooperation in the Inner Oslofjord, The Royal Norwegian Council for Scientific and Industrial Research, and The Norwegian State Pollution Control Authority. 


\section{LITERATURE CITED}

Burkill, P. H., Mantoura, R. F. C., Llewellyn, C. A., Owens, N. J. P. (1987). Microzooplankton grazing and selectivity of phytoplankton in coastal waters. Mar. Biol. 93: 581-590

Chan, A. T. (1980). Comparative physiological study of marine diatoms and dinoflagellates in relation to irradiance and cell size. II. Relationship between photosynthesis, growth, and carbon/chlorophyll a ratio. J. Phycol. 16: 428-432

Dortch, Q., Clayton, J. R., Jr, Thoresen, S. S., Ahmed, S. I. (1984). Species differences in accumulation of nitrogen pools in phytoplankton. Mar. Biol. 81: 237-250

Dortch, Q., Clayton, J. R., Jr, Thoresen, S. S., Cleveland, J. S., Bressler, S. L., Ahmed, S. I. (1985). Nitrogen storage and use of biochemical indices to assess nitrogen deficiency and growth rate in natural plankton populations. J. mar. Res. 43: 437-464

Droop, M. R. (1983). 25 years of algal growth kinetics. A personal view. Botanica mar. 26: 99-112

Eppley, R. W., Peterson, B. J. (1979). Particulate organic matter flux and planktonic new production in the deep ocean. Nature, Lond. 282: 677-680

Flynn, K. J., Butler, I. (1986). Nitrogen sources for the growth of marine microalgae: role of dissolved free amino acids. Mar. Ecol. Prog. Ser. 34: 281-304

Gallegos, C. L. (1989). Microzooplankton grazing on phytoplankton in the Rhode River, Maryland: nonlinear feeding kinetics. Mar. Ecol. Prog. Ser. 57: 23-33

Gifford, D. J. (1988). Impact of grazing by microzooplankton in the Northwest Arm of Halifax Harbour, Nova Scotia. Mar. Ecol. Prog. Ser. 47: 249-258

Glibert, P. M. (1988). Primary productivity and pelagic nitrogen cycling. In: Blackburn, T. H., Sørensen, J. (eds.) Nitrogen cycling in coastal marine environments. Wiley, Chichester, p. 3-31

Glibert, P. M., McCarthy, J. J. (1984). Uptake and assimilation of ammonium and nitrate by phytoplankton: indices of nutritional status for natural assemblages. J. Plankton Res. 6: $677-697$

Goldman, J. C., Glibert, P. M. (1983). Kinetics of inorganic nitrogen uptake by phytoplankton. In: Carpenter, E. J., Capone, D. G. (eds.) Nitrogen in the marine environment. Academic Press, New York, p. 233-274

Goldman, J. C., McCarthy, J. J. (1978). Steady state growth and ammonium uptake of a fast-growing diatom. Limnol. Oceanogr. 23: 695-703

Harrison, P. J., Conway, H. L., Holmes, R. W., Davis, C. O. (1977). Marine diatoms grown in chemostats under silicate or ammonium limitation. III. Cellular chemical composition and morphology of Chaetoceros debilis, Skeletonema costatum, and Thalassiosira gravida. Mar. Biol. 43: 19-31

Harrison, P. J., Parslow, J. S., Conway, H. L. (1989). Determination of nutrient uptake kinetic parameters: a comparison of methods. Mar. Ecol. Prog. Ser. 52: 301-312

Harrison, W. G. (1983). Uptake and recycling of soluble reactive phosphorus by marine microplankton. Mar. Ecol. Prog. Ser. 10: 127-135

Healey, F. P., Hendzel, L. L. (1980). Physiological indicators of nutrient deficiency in lake phytoplankton. Can. J. Fish. Aquat. Sci. 37: 442-453

Hecky, R. E., Kilham, P. (1988). Nutrient limitation of phytoplankton in freshwater and marine environments: a review of recent evidence on the effects of enrichment. Limnol. Oceanogr. 33: 796-822

Holm-Hansen, O., Lorenzen, C. J., Holmes, R. W., Strickland, J. D. H. (1965). Fluorometric determination of chlorophyll. J. Cons. perm. int. Explor. Mer 30: 3-15
Kristiansen, S. (1983). Urea as a nitrogen source for the phytoplankton in the Oslofjord. Mar. Biol. 74: 17-24

Landry, M. R., Haas, L. W., Fagerness, V. L. (1984). Dynamics of microbial plankton communities: experiments in Kaneohe Bay, Hawaii. Mar. Ecol. Prog. Ser. 16: 127-133

Landry, M. R., Hassett, R. P. (1982). Estimating the grazing impact of marine microzooplankton. Mar. Biol. 67: 283-288

Langdon, C. (1987). On the causes of interspecific differences in the growth-irradiance relationship for phytoplankton. Part I. A comparative study of the growth-irradiance relationship of three marine phytoplankton species: Skeletonema costatum, Olisthodiscus luteus and Gonyaulax tamarensis. J. Plankton Res. 9: 459-482

Miyata, K., Hattori, A. (1986). A simple fractionation method for determination of phosphorus components in phytoplankton: application to natural populations of phytoplankton in summer surface waters of Tokyo Bay. J. oceanogr. Soc. Japan 42: 255-265

Miyata, K., Hattori, A., Ohtsuki, A. (1986). Variation of cellular phosphorus composition of Skeletonema costatum and Heterosigma akashiwo grown in chemostats. Mar. Biol. 93: 291-297

Myklestad, S., Sakshaug, E. (1983). Alkaline phosphatase activity of Skeletonema costatum populations in the Trondheimsfjord. J. Plankton Res. 5: 557-564

Nordli, E. (1957). Experimental studies on the ecology of Ceratia. Oikos 8: 200-265

Olsen, Y., Østgaard, K. (1985). Estimating release rates of phosphorus from zooplankton: model and experimental verification. Limnol. Oceanogr. 30: 844-852

Paasche, E. (1973). The influence of cell size on growth rate, silica content, and some other properties of four marine diatom species. Norw. J. Bot. 20: 197-204

Paasche, E. (1980). Silicon content of five marine plankton diatom species measured with a rapid filter method. Limnol. Oceanogr. 25: 474-480

Paasche, E., Erga, S. R. (1988). Phosphorus and nitrogen limitation of phytoplankton in the inner Oslofjord (Norway). Sarsia 73: 229-243

Paasche, E., Kristiansen, S. (1982). Ammonium regeneration by microzooplankton in the Oslofjord. Mar. Biol. 69: 55-63

Paranjape, M. A. (1987). Grazing by microzooplankton in the eastern Canadian arctic in summer 1983. Mar, Ecol. Prog. Ser. 40: 239-246

Rhee, G.-Y., Gotham, I. J. (1980). Optimum N:P ratios and coexistence of planktonic algae. J. Phycol. 16: 486-489

Ryther, J. H., Dunstan, W. M. (1971). Nitrogen, phosphorus, and eutrophication in the coastal marine environment. Science 171: 1008-1013

Ryther, J. H., Guillard, R. R. L. (1959). Enrichment experiments as a means of studying nutrients limiting to phytoplankton production. Deep Sea Res. 6: 65-69

Sakshaug, E., Granéli, E., Elbrächter, M., Kayser, H. (1984). Chemical composition and alkaline phosphatase activity of nutrient-saturated and P-deficient cells of four marine dinoflagellates. J. exp. mar. Biol. Ecol. 77: 241-254

Sakshaug, E., Olsen, Y. (1986). Nutrient status of phytoplankton blooms in Norwegian waters and algal strategies for nutrient competition. Can. J. Fish. Aquat. Sci. 43: 389-396

Smayda, T. (1974). Bioassay of the growth potential of the surface water of lower Narragansett Bay over an annual cycle using the diatom Thalassiosira pseudonana (oceanic clone, 13-1). Limnol. Oceanogr. 19: 889-901

Sommer, U. (1983). Nutrient competition between phytoplankton species in multispecies chemostat experiments. Arch. Hydrobiol. 96: 399-416 
Strathmann, R. R. (1967). Estimating the organic carbon content of phytoplankton from cell volume or plasma volume. Limnol. Oceanogr. 12: 411-418

Suzuki, R., Fujita, Y. (1986). Chlorophyll decomposition in Skeletonema costatum: a problem in chlorophyll determination of water samples. Mar. Ecol. Prog. Ser. 28: 81-85

Tilman, D. (1980). Resources: a graphical-mechanistical approach to competition and predation. Am. Nat. 116: 362-393

Turpin, D. H. (1988). Physiological mechanisms in phyto-

This article was submitted to the editor plankton resource competition. In: Sandgren, C. D. (ed.) Growth and reproductive strategies of freshwater phytoplankton. Cambridge Univ. Press, Cambridge, p. 316-368 Venrick, E. L., Beers, J. R., Heinbokel, J. F. (1977). Possible consequences of containing microplankton for physiological rate measurements. J. exp. mar. Biol. Ecol. 26: 55-76

Yentsch, C. M., Yentsch, C. S., Strube, L. R. (1977). Variations in ammonium enhancement, an indication of nitrogen deficiency in New England coastal phytoplankton populations. J. mar. Res. 35: 537-555

Manuscript first received: April 17, 1990

Revised version accepted: October 12, 1990 